
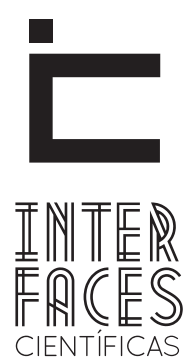

EDUCAÇÃO

ISSN IMPRESSO 2316-333X

ISSN ELETRÔNICO 2316-3828

\title{
HISTORIOGRAFIA DA EDUCAÇ̃̃O: A IMPRENSA ENQUANTO FONTE DE INVESTIGAÇÃO
}

Adriana Salvaterra Pasquini ${ }^{1}$

\section{RESUMO}

Essa pesquisa é uma análise acerca da historiografia da Educação brasileira a partir da diversidade de fontes históricas, sendo a imprensa aqui, eleita como principal fonte histórica. A utilização da imprensa, pedagógica ou não, como fonte de pesquisa possibilita a compreensão da educação enquanto processo histórico vinculado aos embates, fruto das relações sociais. A imprensa fornece, também, elementos que esclarecem os debates realizados na esfera social, e que nem sempre estão próximos dos setores formais da prática escolar. 0 objetivo é discutir a contribuição da imprensa enquanto fonte de pesquisa para a historiografia da educação. Parte-se do pressuposto de que a análise da realidade educacional brasileira requer que a considere no contexto social no qual ela é inserida. Isto implica no conhecimento das relações econômicas e culturais que envolvem a história. Cabe questionar: Como imprensa e educação se coadunam enquanto objetos de análise do contexto educacional brasileiro? Quanto a sua metodologia, trata-se de uma pesquisa bibliográfica na área da História da Educação. Em termos de resultados, concluiu-se que a pesquisa possibilitou a compreensão de que a imprensa traz inscrita em suas páginas elementos históricos que, seguramente, proporcionam o entendimento não só do processo educacional em si, mas dos debates havidos na sociedade em nome da realização de uma forma determinada de relação social na qual a educação desempenhava e desempenha papel relevante.

\section{PALAVRAS-CHAVE}

Historiografia da Educação. Fontes Históricas. Imprensa. 


\section{ABSTRACT}

This research is an analysis of the Brazilian educational historiography from the diversity of historical sources, and the press, elected as primary historical source. The use of the press, pedagogical or not, as the main source of research enables the understanding of education as a historical process linked the conflicts that are the results of social relations. The press also provides elements that clarify the discussions in the social sphere, and which not always are close of formal sectors of the school practice. The aim is to discuss the contribution of the press as a research source for the history of education. We assumed that the analysis of the Brazilian educational reality requires that we consider the social context in which it is inserted. This implies knowledge of economic and cultural relations involving the history. Question: In what manner the press and education fit while objects of analysis of Brazilian educational context? The methodology consists of a bibliographical research in the area of the History of Education. The research led to understanding that the press brings inscribed on its pages historical elements that surely provide an understanding not only of the educational process itself, but the discussions held in society in the name of accomplishing a particular form of social relationship in which education played and plays an important role.

\section{KEYWORDS}

Historiography of Education. Historical Sources. Press.

\section{RESUMEN}

Esta investigación es un análisis sobre la historiografía de la educación brasileña de la diversidad de las fuentes históricas. Ella utiliza la prensa educativa, como la fuente principal de la investigación. El objetivo es discutir la investigación histórica con fuentes documentales, como instrumento para comprender el proceso histórico de la educación, porque aporta elementos que representen para las discusiones en la esfera social y que no siempre están cerca de los sectores formales de la escuela práctica. Asumimos que el análisis de la realidad educativa brasileña requiere considerar el contexto social en que se inserta. Esto implica el conocimiento de las relaciones económicas y culturales que involucran la historia. Así, la investigación actual se centra en conocimiento que respondería a la pregunta inicial: ¿De qué manera la prensa y educación ajustan mien- tras objetos de análisis del contexto educativo brasileño? La metodología consiste en un estudio bibliográfico en el ámbito de la historia de la educación. La literatura empleada en investigación actual favorece la conclusión de que el estudio permitió darse cuenta de que la prensa lleva escrito en sus páginas. Elementos históricos que han proporcionado la comprensión, no sólo del propio proceso educativo, sino también, de los debates que se han producido en la sociedad en nombre de una forma particular de relación social, en la cual la educación ha jugado y juega un papel relevante.

\section{PALABRAS CLAVE}

Historiografía de la Educación. Fuentes Históricas. Prensa. 


\section{INTRODUÇ̃̃̃o}

Nas últimas décadas ampliou-se no Brasil o número de estudos históricos sobre a educação. A análise da realidade educacional brasileira permite sistematizar historicamente a interpretação da educação e requer considerá-la no contexto social na qual se insere. Isso implica conhecimento das relações culturais que envolvem a interpretação da história. A referida análise só se justifica quando são considerados seus aspectos históricos, uma vez que parte-se do pressuposto que educação e história são indissociáveis.

Campo fértil para a pesquisa, o tema suscita um grande número de pesquisas sobre a historiografia da educação, bem como sobre a diversidade de fontes a serem utilizadas na elaboração dessa escrita, entre elas destacam-se os temas relacionados à imprensa periódica pedagógica ou não.

Neste texto, contextualizar-se-á teórica e historicamente a utilização da imprensa enquanto objeto de pesquisa para a historiografia da educação, buscando responder à seguinte indagação: Em que medida imprensa e educação se coadunam com a análise do contexto educacional brasileiro?

Primeiramente, analisar-se-á a imprensa como fonte de pesquisa para a educação, por meio de uma breve análise histórica da imprensa no Brasil e, de sua consolidação como fonte de pesquisa para a história da educação. Posteriormente, discutir-se-á a utilização da imprensa enquanto fonte documental para a compreensão do processo histórico da educação, uma vez que as mesmas fornecem elementos que clarificam os debates realizados na esfera social, e que nem sempre estão próximos dos setores formais da prática escolar.

\section{A ORIGEM DA IMPRENSA NO BRASIL}

O desenvolvimento da imprensa, no Brasil, teve início com a chegada da família real portuguesa, em
1808. Até então era proibida toda e qualquer atividade de imprensa, o que era uma peculiaridade da América Portuguesa, uma vez que nas demais colônias da América a imprensa se fazia presente desde o século XVI. A família real trouxe na bagagem um maquinário para impressão (até então inexistente no país), que foi comprado para a Secretaria de Estrangeiros e da Guerra, e instalado nos baixos da residência do futuro conde da Barca. A realeza portuguesa abria caminho para o início da imprensa brasileira, que foi eficiente tanto na propagação do pensamento conservador quanto das ideias inovadoras no campo intelectual.

A Imprensa Régia estabelecida pela corte tinha a função de gerenciar e examinar todo material que se mandasse publicar e fiscalizar para que não se imprimisse nenhum livro ou panfleto que manifestasse ideias contrárias a religião, ao governo e aos bons costumes. Nenhum material poderia ser impresso sem o exame dos censores reais, era a censura à imprensa.

O jornal Gazeta do Rio de Janeiro foi o primeiro periódico a sair dessa oficina no dia 10 de setembro de 1808, o impresso que continha textos extraídos da Gazeta, de Lisboa ou de jornais ingleses, foi o único jornal a circular na principal cidade do país durante 13 anos (1808-1821). Ao caracterizar a Gazeta do Rio de Janeiro, Sodré o descreve:

Era um pobre papel impresso, preocupado quase que
tão somente com o que se passava na Europa, de qua-
tro páginas in 4., poucas vezes mais, semanal de início,
trisemanal, depois, custando a assinatura semestral
$\$ 800$, e 80 réis o número avulso. Jornal oficial, feito na
imprensa oficial, nada nele constituía atrativo para o
púbico nem essa era a preocupação dos que o faziam,
como a dos que o haviam criado. (SODRÉ, 1966, p. 23).

O conteúdo da Gazeta do Rio de Janeiro estava restrito a informações sobre os príncipes da Europa, tais 
como seus estados de saúde e natalícios, trazia, também, alguns documentos de ofícios que ilustravam as páginas do periódico, cujo principal objetivo era o de agradar à Coroa. A partir das informações contidas no único periódico do Brasil, poderia ser afirmado que havia um ambiente harmonioso, sem conflitos de classe, uma vez que os embates sociais na luta pela democracia permaneciam longe das páginas do jornal.

Cumpre destacar ainda o jornal Correio Brasiliense, publicado em Londres por Hipólito José da Costa Furtado de Mendonça que chegava de Londres clandestinamente ao Brasil e trazia em seu conteúdo textos criticavam a Coroa Portuguesa e faziam apologia à independência do Brasil. Hipólito José da Costa estava exilado na Inglaterra desde o final de 1805, fugindo da Inquisição portuguesa que aqui se estabelecera. Hipólito fundou o Correio Braziliense, cujo número inaugural foi publicado em $1^{\circ}$ de junho de 1808 , expressava amplas articulações políticas. 0 jornal de Hipólito apresentava-se declaradamente como formador de opinião, de caráter doutrinário muito mais que informativo, com predominância da moral e da ética, desvinculado de uma finalidade revolucionária.

De acordo com Periotto (2004), Hipólito da Costa assumiu os princípios dos ideais liberais, já ratificados na Europa. No seu entendimento, o Brasil só atingiria pleno desenvolvimento quando as forças de trabalho passassem a ser as mesmas executadas nas nações onde o sistema capitalista se consolidara. Dessa maneira, pode-se afirmar que as ideias de Hipólito da Costa defendiam os interesses da dominante, mesmo ao propor o fim da escravidão o fazia com base nas exigências da produção e nos pactos com as nações burguesas.

O papel histórico exercido na imprensa brasileira pelo Correio Brasiliense apresenta inúmeras controvérsias, se por um lado alguns historiadores afirmam que o mesmo se constitui em um marco da imprensa nacional, pelo seu conteúdo, qualidade e pertinência dos assuntos apresentados, do outro lado pesquisadores utilizam o argumento de que o fato de ser o jornal escrito, editado e impresso fora do país o mesmo já não refletia as reais condições e anseios da sociedade brasileira. 0 Correio Brasiliense deixou de circular no ano da Independência, o que na análise de Sodré,

Não foi coincidência o seu desaparecimento no ano da independência. Seu pensamento a respeito, aliás, era claro: "Ninguém deseja mais do que nós as reformas úteis, mas ninguém aborrece mais do que nós sejam essas reformas feitas pelo povo. Reconhecemos as más consequências dêsse modo de reformar. Desejamos as reformas, mas feitas pelo govêrno, e urgimos que 0 governo as deve fazer enquanto é tempo, para que se evite serem feitas pelo povo". As palavras são de 1811, mas Hipólito da Costa permaneceu fiel ao que elas traduziam de conteúdo político. Essa era, sem dúvida também a posição da classe dominante, no Brasil e na época. Mas esta evoluiu, progressivamente, esposando, em 1822, a solução da Independência. Hipólito da Costa não a esposou; aceitou-a. Foi ultrapassado pelos acontecimentos e, portanto, pela parte mais importante de seu público. E o Correio Brasiliense perdeu a razão de existir, por isso mesmo. (SODRÉ, 1966, p. 33).

A proibição à imprensa, marcada inclusive pela destruição de máquinas tipográficas (a censura prévia foi estabelecida mesmo antes de publicada a primeira edição da Gazeta do Rio de Janeiro), encontravam justificativas no fato de que o papel desempenhado pela imprensa deveria ser doutrinário, capaz de influenciar a opinião pública, ou seja, de propaganda ideológica.

A discussão sobre o desenvolvimento da imprensa periódica no Brasil, no período que corresponde à sua independência de Portugal, só é possível se considerar-se as condições políticas, sociais e econômicas da época. Pensar que a separação entre Brasil e Portugal se deu de modo súbito e uniforme é no mínimo ingênuo, uma vez que tal processo envolveu mudanças políticas e econômicas profundas e determinadas por inúmeros fatores nacionais e internacionais.

A imprensa brasileira não passou ilesa pela efervescência causada em razão do processo de independência da nação. Sofreu forte impacto, pois o mesmo instrumento despertava interesses antagônicos: da- 
queles que aceitaram a independência e de outros que a aceitaram tardiamente e ainda daqueles que a almejavam de outra forma.

De acordo com Sodré (1966), foram poucos os periódicos que expuseram uma luta doutrinária em favor da Independência ou que demonstraram as reais razões de sua consolidação. Dentre tantos se destacam o Revérbero Constitucional Fluminense, fundado em 15 de setembro de 1821, sendo este o melhor instrumento de reivindicações da sociedade da época e 0 Constitucional, que passou a circular em 10 de maio de 1822, na Bahia. Ambos perseguidos e fechados, respectivamente, pela ação da elite brasileira e pelos militares portugueses. No que concerne ao relevante papel da imprensa nos movimentos políticos desse período, Tania Regina de Luca (2011, p. 134) afirma:

O caráter doutrinário, a defesa apaixonada de ideias e a intervenção no espaço público caracterizam a imprensa brasileira de grande parte do século XIX, que, é bom lembrar, contava com contingente diminuto de leitores, tendo em vista as altíssimas taxas de analfabetismo. Os aspectos comerciais da atividade eram secundários diante da tarefa de interpor-se nos debates e dar publicidade às propostas, ou seja, divulgá-las e torná-las conhecidas. A imprensa teve papel relevante em momentos políticos decisivos, como a Independência, a Abdicação de D. Pedro I, a Abolição e a República.

No período da independência, a imprensa concentrava-se em importantes núcleos de poder político e econômico como Rio de Janeiro, Bahia e Pernambuco, estes se estabeleciam como propagadores culturais. Diante das tortuosas discussões ocorridas no processo de Independência emergiu-se um periódico de pequeno formato, contendo quatro páginas e escrito por no máximo duas pessoas e denominado o Pasquim. Considerado como a melhor representação da sociedade brasileira, em razão de sua autenticidade, clareza de linguagem que traduzia com fidedignidade a manifestação popular da época, expressada de forma democrática, porque o jornalismo não era categoria profissional e qualquer pessoa letrada não encontrava a menor dificuldade para rodar o seu pasquim. Em relação às características da primeira geração da imprensa brasileira Morel e Barros (2003, p. 49) se manifestam:

Havia, é certo, órgãos mais bem comportados, que se pretendiam apenas noticiosos, geralmente no campo econômico ou literário. Mas a imprensa como instrumento político, de convencimento, revelando as paixões e conflitos, preponderava - fosse conservadora ou contestadora, exaltada ou moderada. 0 estilo panfletário, pasquineiro, dava tônica, independentemente da colaração política. Por tudo isso, a imprensa da primeira metade do século XIX no Brasil privilegiava o doutrinário, o propagandístico, em detrimento do factual e descritivo.

Encerrada a fase artesanal da imprensa, ocorrida em razão das inovações técnicas decorrentes da segunda metade do século XIX, o jornal passa a se caracterizar como pequenas empresas. No período denominado Império a imprensa recebeu, como em qualquer outro momento histórico, os reflexos das condições sociais postas. Com o avanço territorial do café, a exploração do trabalho escravo, o predomínio da Corte tornou-se mais coesa e fez surgir então, novos líderes políticos provenientes não mais das distantes áreas açucareiras, nem mesmo das zonas de mineração, mas da província do Rio de Janeiro, principal região produtora de café, emergia uma nova estrutura social.

Outra importante característica da imprensa nesse período é a aproximação entre a imprensa e a literatura na fase anterior não havia espaço para os textos literários. A publicação era restrita a revistas especializadas de curto tempo de circulação, dividindo a imprensa política da imprensa literária. Dentre tantos nomes que se fizeram presentes na aproximação entre a imprensa e a literatura, José de Alencar (1829-1877) se destacou como principal inspirador de uma imprensa genuinamente nacionalista. Iniciou sua atividade literária no Correio Mercantil e no O Diário do Rio de Janeiro e ficou conhecido como 0 homem das letras. 0 romancista, dramaturgo, advogado, jornalista e político bra- 
sileiro dinamizou a imprensa nacional, ao publicar nos respectivos jornais romances que abordavam o cotidiano da época em forma de folhetins.

O primeiro romance a ser escrito em 1856 foi Cinco minutos, com o mesmo formato. Em seguida o autor escreveu o romance A viuvinha, que apresentava a vida e os costumes da sociedade carioca do segundo reinado. Porém foi com o romance 0 guarani que José de Alencar se consagrou, pois o conteúdo dos textos agradou aos leitores que percebiam em suas páginas questões políticas da sociedade discutidas e representadas por personagens que refletiam o cotidiano de um povo. Ao analisar a relação entre a literatura, a imprensa periódica e a profissionalização intelectual no início do século XX, Sérgio Miceli (2001, p. 54) aponta:

No início do século XX, o jornalismo tornara-se um ofício compatível com o status de escritor [...] 0 que fora para alguns autores românticos (por exemplo, Alencar e Macedo) uma atividade e uma prática tolerada, tornando-se depois para certos escritores da geração de 1870 (por exemplo, Machado de Assis) uma atividade regular, que thes proporcionava uma renda suplementar cada vez mais indispensável.

A oposição à monarquia se ampliou, o que possibilitou o golpe político que instaurou a república no Brasil em 1889, porém, a imprensa permanecia, constituída de grandes jornais que se mantinham pelo prestígio e força dos republicanos e da combatividade dos monarquistas, ao passo que do outro lado os pequenos jornais caracterizavam-se pela efemeridade na circulação, desaparecendo após os períodos de agitação. Outra característica que marcou o período foi a designação de alguns profissionais da imprensa para funções políticas, dos quais destacam-se Salvador de Mendonça (1841-1913), Rui Barbosa (18491923), que a rigor não era considerado diretamente ligado à imprensa, porém se destacou na mesma à véspera da queda da monarquia, e Quintino Bocaiúva (1836-1912), jornalista e político brasileiro considerado a figura mais importante do periodismo brasileiro na época (SODRÉ, 1966).
Os jornais de estrutura simples, compostos por folhas tipográficas, deram lugar às empresas jornalísticas, com estrutura específica. Essa transformação da imprensa estava atrelada à ascensão burguesa e ao avanço do sistema capitalista. "É agora muito mais fácil comprar um jornal do que fundar um jornal; é ainda mais prático comprar a opinião do jornal do que comprar o jornal” (SODRÉ, 1966, p. 315).

Percebe-se que não há neutralidade ou imparcialidade e ainda, um periódico não está alheio à realidade histórica, uma vez que veiculam informações e análises (quase sempre unilaterais), sobre aspectos comerciais, políticos, religiosos, econômicos. Desta forma, acaba-se por constituir um objeto que veicula e manipula interesses de classes antagônicas, assumindo papel formador e regulador da opinião pública.

\section{A IMPRENSA ENQUANTO FONTE PARA A HISTORIOGRAFIA DA EDUCAÇÃO BRASILEIRA}

Nas últimas duas décadas ampliou-se no Brasil o número de estudos históricos sobre a educação. Campo fértil para a pesquisa, o tema suscita um grande número de pesquisas. A imprensa periódica ou pedagógica traz, inscrita em suas páginas elementos históricos que, seguramente, proporcionam o entendimento não só do processo educacional em si, mas dos debates havidos na sociedade em nome da realização de uma forma determinada de relação social e, na qual a educação desempenhava e desempenha papel relevante.

0 estudo da imprensa brasileira tem colaborado para o delineamento de um fecundo painel dos fatos e acontecimentos da história nacional, pois trazem impressos os discursos e procedimentos dos indivíduos envolvidos na construção da nação brasileira e, notadamente, fizeram aflorar os interesses dos diversos grupos sociais em batalha pelo comando do poder político e econômico da sociedade brasileira. 
As discussões de Neves e outros autores (2006) pontuam a importância da imprensa para as novas análises sobre política e cultura, na medida em que, segundo ela, velhos temas são revisitados por meio de abordagens teóricas capazes de extrair uma gama maior de conexões entre os fatos e o processo histórico no qual a sociedade da época está inserida:

0 redimensionamento da imprensa como fonte documental - na medida em que expressa discursos e expressões de protagonistas - possibilitou a busca de novas perspectivas para a análise dos processos históricos. Dessa forma, superou-se a perspectiva limitada de identificar a imprensa como portadora dos "fatos" e da "verdade". Deixaram-se também para trás posturas preconcebidas, que a interpretavam, desdenhosamente, como mero veículo de idéias ou forças sociais, que, por sua vez, eram subordinadas estritamente por uma infra-estruturasócio-econômica. (NEVES et al., 2006, p. 10).

Nessa perspectiva, cumpre destacar que os fazeres que expliquem os acontecimentos produzidos pelos homens são construídos em sua multiplicidade pela ação desses homens e, no qual, aquele que pesquisa é também sujeito do seu tempo, que vive e sofre as influências do movimento e das contradições sociais. É importante que o historiador tenha clareza de que a História não se resume ao estudo de fatos e supere o olhar comum sobre as relações do passado, como determina José Maria de Paiva: "A história não se dá sem o historiador. Este não é um ente abstrato, mas um ser vivo, membro de um grupo social" (PAIVA, 2006, p. 14).

As discussões de Hobsbawn (1998) sinalizam que a reflexão sistemática bem como os objetivos e os objetos da historiografia não podem ser considerados enquanto elementos distintos de sua escrita, ou seja, a narrativa historiográfica não se distingue da própria escrita da história:

Todo ser humano tem consciência do passado (definido como o período imediatamente anterior aos eventos registrados na memória de um indivíduo) em virtude de viver com pessoas mais velhas. Provavelmente todas as sociedades que interessam ao historiador tenham um passado, pois mesmo as colônias mais inovadoras são povoadas por pessoas oriundas de alguma sociedade que já conta com uma longa história. Ser membro de uma comunidade humana é situar-se em relação ao seu passado (ou da comunidade), ainda que apenas para rejeitá-lo. 0 passado é, portanto, uma dimensão permanente da consciência humana. 0 problema para os historiadores é analisar a natureza desse "sentido do passado" na sociedade e localizar suas mudanças e transformações. (HOBSBAWN, 1998, p. 22).

A crença normalmente existente de que o presente consiste na reprodução do passado, acarreta, segundo esse autor, um ritmo positivamente lento de mudança histórica, caso contrário não consistiria numa realidade concreta. Ao se retomar o percurso dos antepassados, não se realiza automaticamente e os mesmos já não são meras repetições de algo que já ocorreu, mas se tornam expressões que são definitivamente diferentes das ações anteriores, por isso é preciso considerar que, para se compreender as relações do passado se faz necessário analisar as relações que se dão no presente e não o contrário é o que apresenta a análise feita por Engels no texto: Sobre o papel do trabalho na transformação do macaco em homem ${ }^{3}$. Dessa forma, o entendimento do processo histórico implica na consideração do mundo real, uma vez que compreender a sociedade implica, sobretudo, no entendimento da história, superando a visão de que as ideias dominam e determinam as condições materiais.

A análise do processo histórico suscita discussões que assumem crucial importância para os historiadores, uma vez que todo conjunto de reflexões sobre a história acarreta, pois, uma questão não somente funcional, mas conceitual. Acerca dessa questão, Saviani (2006, p. 7) assim se posiciona:

Em visão retrospectiva, é possível constatar que a história só se pôs como um problema para o homem, isto me só emergiu como que necessita ser compreendido e explicado, a partir da época moderna. A razão disso

3. Friedrich Engels. Sobre o papel do trabalho na transformação do macaco em homem. Disponivel em: <http://www.vermelho.org.br>. Acesso em: 22 jun. 2013. 
é relativamente simples. Enquanto os homens garantiam a própria existência no âmbito de condições dominantemente naturais, relacionando-se com a natureza através da categoria da "providência", o que implicava o entendimento de o meio natural the fornecia os elementos básicos de subsistência os quais eram apropriados em estado bruto exigindo quando muito, processos rudimentares de transformação que, por si mesmo, resultavam em formas de vida social estáveis sintonizadas com uma visão cíclica do tempo, não se punha a necessidade de compreender a razão, o sentido e a finalidade das transformações que se processam no tempo, isto é, não se colocava o problema da história.

Dessas acepções, pode-se ressaltar que as condições de produção da existência ou de sobrevivência da vida humana, são predominantemente sociais, ou seja, os próprios homens as produzem submetendo à natureza. Não obstante Saviani (2006) pontua que o homem, além de um ser histórico, busca apropriar-se de sua historicidade.

Com efeito, evidenciam-se as contribuições de Zélia Leonel no campo da História da Educação ao discutir a dicotomia entre História e Educação: “Não existe História da educação. A educação é parte integrante da história, mas a história não é da educação" (LEONEL, 2006, p. 53). A partir dessa reflexão é importante destacar que a educação é aqui entendida em seu sentido mais amplo. Ela extrapola os livros didáticos bem como o ambiente escolar, e é constituída enquanto processo cultural de construção humana, sendo considerada em suas particularidades e compreendida dialeticamente por meio das relações com o contexto econômico, político, cultural e social, ou seja, enquanto consequência das múltiplas determinações sociais.

Nessa perspectiva, é importante destacar que a educação se dá na sua unidade dialética com a totalidade, em um processo que considera os desejos e as necessidades humanas no contexto objetivo do momento histórico em que se vive, constituindo-se em uma atividade humana partícipe do movimento histórico.
O conhecimento, enquanto elaboração, incorporação e transmissão de ideias, valores e crenças, origina-se da atividade humana (fazer), e para ele retorna dialeticamente. Coaduna-se a essas reflexões o posiconamento do filósofo marxista, KarelKosik, ao ressaltar que a práxis consiste numa produção histórica, outrossim, que se torna novo continuamente e se constitui enquanto "unidade do homem e do mundo, da matéria e do espírito, de sujeito e objeto, do produto e da produtividade" (KOSIK, 2002, p. 222). Deste modo, pode-se pensar o homem como aquele que pela sua práxis objetiva constrói a própria realidade, 0 que possibilita conhecê-la na dimensão social e histórica de modo a compreender sua unidade dialética em sua totalidade.

Em consonância com o princípio teórico apresentado e considerando a historicidade do fenômeno educativo, Saviani se pronuncia:

\begin{abstract}
Sabe-se que a educação é um fenômeno próprio dos seres humanos. Assim sendo, a compreensão da natureza da educação passa pela compreensão da natureza humana. Ora, o que diferencia os homens dos demais fenômenos, o que o diferencia dos demais seres vivos, o que o diferencia dos outros animais? A resposta a essas questões também já é conhecida. Com efeito, sabe-se que, diferentemente dos outros animais, que se adaptam à realidade natural tendo sua existência garantida naturalmente, o homem necessita produzir continuamente sua própria existência. Para tanto, em lugar de se adaptar à natureza, ele tem que adaptar a natureza a si, isto é transformá-la. Portanto o que diferencia o homem dos outros animais é o trabalho. E o trabalho se instaura a partir do momento em que seu agente antecipa mentalmente a finalidade da ação. Consequentemente o trabalho não é qualquer tipo de atividade, mas uma ação adequada a finalidades. É, pois, uma ação intencional. (SAVIANI, 1995, p. 15).
\end{abstract}

As relações de trabalho estabelecidas historicamente são condicionantes da finalidade da educação. No entanto, a ambiguidade contida nas análises sobre a relação entre o conhecimento científico e o trabalho acarretam experiências fragmentadas que refletem a compreensão do trabalho e da educação como categorias a-históricas. 
Considerando tais implicações, pode-se dizer que a pesquisa histórica com fontes documentais tem se constituído em um rico instrumento para a investigação em história da educação, principalmente porque fornece elementos que clarificam os debates realizados na esfera social, e que nem sempre estão próximos dos setores formais da prática escolar. Ela possibilita, ainda, ao historiador, que se coloca diante das fontes como sujeito concreto do tempo presente, compreender o passado de acordo com suas potencialidades, “toda história é história do presente, realçando o caráter de subjetividade, que sustenta e põe a realidade que lhe cabe" (PAIVA, 2006, p. 115). No entanto, o ato de pensar a educação por meio de fontes históricas e documentais é às vezes obstaculizado pelo desconhecimento e pela inadequada catalogação e conservação dos acervos, fato que muitas vezes inviabiliza o trabalho de se guardar a memória histórica do país.

Cabe salientar que diante da multiplicidade de pesquisas realizadas no campo educacional, destaca-se a utilização da imprensa - não necessariamente a pedagógica - como importante fonte e objeto da pesquisa histórico-educacional. Esse tipo de pesquisa contribui, tanto para a análise específica da realidade de um determinado momento histórico, quanto para a utilização de objetos de pesquisa, aparentemente desvinculados da educação, que se constituem em diferentes fontes de informação. No Brasil, a pesquisa educacional realizada com a imprensa como fonte histórica documental avançou de modo significativo no meio acadêmico nos últimos anos, o que possibilitou um corpus de fontes documentais pouco estudados até então.

Os estudos que utilizam a imprensa como referência para a compreensão da realidade brasileira, nos últimos tempos, tem-se desenvolvido muito nos meios acadêmicos, notadamente na área da história. Assim, a conjugação da informação jornalística com a metodologia histórica tem-se mostrado produtiva para ambas as áreas. Tanto a imprensa ganhou na forma de tratar suas informações e no enriquecimento de sua própria história, como a história propriamente dita encontrou um novo manancial de dados, a partir do qual pode ampliar seu ângulo de visão e promover interpretações mais abrangentes, que consigam reproduzir de forma mais eficiente, a dinâmica social. (CARVALHO; INÁCIO FILHO, 2007).

0 redimensionamento da imprensa como fonte documental, possibilitou uma nova análise da palavra impressa, frequentemente vista como um registro sequencial de fatos desvinculados das relações estabelecidas historicamente. Pode-se afirmar que a história é um contexto bem maior que uma sequência de datas e não se restringe aos fatos ou acontecimentos do passado, antes de tudo significa a luta pela vida existente entre os homens, que se expressa como instrumento de transmissão do patrimônio cultural de um povo, como afirma Venâncio Filho (1945, p. 374):

\begin{abstract}
[...] não faltará à nossa História a pintura sugestiva dos homens e das coisas ou os travamentos das relações e costumes que são a imprimidura indispensável ao desenrolar dos acontecimentos, conforme ele mesmo desejava e tantas vezes fez com o vigor do seu pensamento, incomparável pelo fundo e pela forma. E diante de tantas fontes históricas, ver-se-á que a história da educação se confundirá com a nossa própria história.
\end{abstract}

Educação e imprensa, dois elementos aparentemente desvinculados, mas que se revelam como unidades estruturais que possibilitam a análise de diferentes grupos representantes de determinadas forças de poder, sejam elas expressas nas questões políticas, religiosas ou educacionais. Nesse sentido não se pode pensar em educação sem antes considerar sua ação como um processo de "não neutralidade", ou seja, toda e qualquer atitude educativa institucionalizada ou não, possui uma intencionalidade, e de certo modo responde direta ou indiretamente ao seguinte questionamento: Que tipo de homem pretende-se formar? O homem é um ser social e, são consideradas as condições materiais em que vive, que se encontram as bases para suas relações tanto material quanto cultural. Pode-se então, afirmar que no ato de fazer a história o homem, numa relação dialética, também, é feito por ela. 
A imprensa adquire importância como fonte historiográfica e em muito contribui para se historiar as relações políticas expressas no pensamento educacional. No âmbito filosófico-epistemológico, a imprensa se faz num espaço privilegiado de disputa pela hegemonia nas sociedades ocidentais, mesmo porque o conhecimento é um dos ambientes onde se travam as disputas pela direção e dominação da formação econômica e social, tornando-se um instrumento de força material utilizada pelos que desejam a consolidação social.

Percebe-se que a imprensa passou a ser considerada como um aspecto vinculado ao processo educacional na medida em que facilmente socializou 0 conhecimento dos povos e, por conseguinte, as ideias necessárias às novas classes em formação. Por isso é mister afirmar que a imprensa possibilita a análise de paradigmas educacionais e filosóficos construídos historicamente.

Desse modo as especificidades apresentadas, fazem da imprensa um objeto de afirmação em grupo e de uma permanente regulação coletiva na medida em que "cada criador está sempre a ser julgado, seja pelo público, seja pelos leitores, seja por outras revistas, seja pelos companheiros de geração" (NÓVOA, 2002, p. 15), pois manifesta pensamentos e valores por meio do diálogo que se faz, mesmo de forma velada, com toda a sociedade.

\section{CONSIDERAÇÕES FINAIS}

Desde sua origem a imprensa brasileira tem colaborado para o delineamento de um fecundo painel dos fatos e acontecimentos da história nacional, pois trazem impressos os discursos e procedimentos dos indivíduos envolvidos na construção da nação brasileira e que, notadamente, fizeram aflorar os interesses dos diversos grupos sociais em batalha pelo comando do poder político e econômico da sociedade brasileira.
Portanto, utilizar-se da imprensa como fonte histórico-educacional implica em uma ação que vá além da educação formal ou da instituição escolar, uma vez que as mesmas não se constituem desvinculadas da sociedade onde estão inseridas. Os artigos apresentados em jornais ou revistas podem auxiliar na realização de reflexões sobre os trâmites que perpassam a educação, revelando a multiplicidade própria do processo, bem como superar a mera discussão sobre ideias e práticas pedagógicas, ações restritas à instituição escolar, dando lugar a uma análise que permite a compreensão das relações construídas socialmente contidas nos discursos educacionais e que são reproduzidas por um determinado grupo com interesses, também, determinados.

Nessa perspectiva, percebe-se que a imprensa tornou-se objeto de referência para a apreensão e compreensão da história da educação. Por ela emergem novas interpretações que, por sua vez, edificam outras concepções de educação, tendo em vista que a conquista da opinião pública se dá por meio de um embate ideológico, ou seja, uma luta de hegemonias políticas, de direções contrastantes.

\section{REFERÊNCIAS}

CARVALHO, C. H.; INÁCIO FILHO, G. Debates educacionais na imprensa: republicanos e católicos no triângulo mineiro - MG (1892-1931). In: SCHELBAUER, A. R.; ARAÚJO, J. C. S. (Org.). História da educação pela imprensa. Campinas: Alínea, 2007, p. 53-84.

ENGELS, F. Sobre o papel do trabalho na transformação do macaco em homem. Disponível em: <http:// www.vermelho.org.br>. Acesso em: 20 jun. 2013.

HOBSBAWM, E. J. Sobre história. São Paulo: Companhia das Letras, 1998.

KOSIK, K. Dialética do Concreto. 4.ed. Rio de Janeiro: Paz e Terra, 1976. 
LEONEL, Z. Tendência Atual da História da Educação. In: SCHELBAUER, A. R.; LOMBARDI, J. C.; MACHADO, M. C. G. (orgs.). Educação em debate: perspectivas, abordagens e historiografia. Campinas: Autores Associados, 2006, p. 53-72.

LUCA, T. R. Fontes impressas: História dos, nos e por meio dos periódicos. In: PINSKY, C. B. (org.) Fontes Históricas. São Paulo: Contexto, 2011.

MICELI, S. Poder, sexo e letras na República Velha. Intelectuais à brasileira. São Paulo: Companhia das Letras, 2001.

MOREL, M.; BARROS, M. M.de. Palaura, Imagem e Poder: o surgimento na imprensa no Brasil do século XIX. Rio de Janeiro: DP\&A, 2003.

NEVES, L. M. B. P.; MOREL, M.; FERREIRA, T. M. B.C. (orgs.). História e imprensa: representações culturais e práticas de poder. Rio de Janeiro: DP\&A/Faperj, 2006, p. 9-15.

NÓVOA, A. A imprensa de educação e ensino: concepção e organização do repertório português. In: CATANI, D. B.; BASTOS, M. H. C. (orgs.) Educação em revista: A imprensa periódica e a história da educação. São Paulo: Escrituras, 2002, p. 35-47.
PAIVA, J. M. Colonização e Catequese. São Paulo: Arké, 2006.

PERIOTTO, M. R. O papel da imprensa no processo de construção da nação: a "vocação pedagógica” do Correio Braziliense. Revista HISTEDBR On-line. Campinas, n.16, p. 61-83, 2004. Disponível em: <http:// www.histedbr.fae.unicamp.br/revista/revis/revis16/ art5_16.pdf>. Acesso em: 21 jun. 2013.

SAVIANI, D. O debate teórico e metodológico no Campo da História e sua Importância para a Pesquisa Educacional. In: SAVIANI, D.; LOMBARDI, J. C.; SANFELICE, J. L. (orgs.). História e história da educação: o debate teórico-metodológico atual. 3.ed. Campinas: Autores Associados, 2006, p. 7-15.

SAVIANI, D. Pedagogia histórico-crítica: primeiras aproximações. 5.ed. Campinas: Autores Associados, 1995.

SODRÉ, N. W. A história da imprensa no Brasil. Rio de Janeiro: Civilização Brasileira, 1966.

VENÂNCIO F. F. Fontes para a história da educação no Brasil. Revista Brasileira de Estudos Pedagógicos, Brasília, v.5, n.15, 1945, p. 529-554. 